\title{
Delayed Neutrophil Apoptosis in Bovine Subclinical Mastitis
}

\author{
P. Boutet, ${ }^{1}$ D. Boulanger, ${ }^{1}$ L. Gillet,${ }^{2}$ A. Vanderplasschen, ${ }^{2}$ \\ R. Closset, ${ }^{1}$ F. Bureau, ${ }^{1}$ and P. Lekeux ${ }^{1}$ \\ ${ }^{1}$ Department of Physiology, and \\ ${ }^{2}$ Department of Infectious and Parasitic Diseases, \\ Faculty of Veterinary Medicine \\ University of Liège, Belgium
}

\begin{abstract}
Bovine subclinical mastitis can be defined as a moderated inflammatory disease characterized by a persistent accumulation of neutrophils in milk. As GMCSFmediated delay of neutrophil apoptosis contributes to the accumulation of inflammatory cells at the site of inflammation in many human diseases, we sought to determine whether subclinical mastitis in cows is also associated with a GMCSF-dependent increase in milkneutrophil survival. We first addressed the hypothesis that GMCSF delays bovine neutrophil apoptosis by activation of the signal transducer and activator of transcription (STAT) family members STAT3 and STAT5, which are critical regulators of the expression of various Bcl-2 family proteins. Granulocyte-macrophage colony-stimulating factor significantly delayed apoptosis of blood neutrophils obtained from healthy cows. In these cells, GMCSF activated STAT5, but not STAT3, and induced an increase in the mRNA of the antiapoptotic Bcl-2 member, Bcl- $\mathrm{x}_{\mathrm{L}}$. Granulocyte-macrophage colony-stimulating factor-dependent STAT5 activation and up-regulation of Bcl- $\mathrm{x}_{\mathrm{L}}$ mRNA were blocked by the Jak inhibitor, AG-490. This inhibition was associated with abrogation of the prosurvival effect of GMCSF, demonstrating a key role for STAT5 in delayed neutrophil apoptosis. We further found that GMCSF expression was increased in milk cells from cows affected with subclinical mastitis. Neutrophils from these cows demonstrated a significant delay of apoptosis as compared with neutrophils obtained from healthy cows and were unresponsive to GMCSF. Active STAT5 complexes were detected in these neutrophils. Finally, in the presence of AG-490, apoptosis was induced and a time-dependent down-regulation of Bcl- $\mathrm{x}_{\mathrm{L}}$ mRNA was observed in milk neutrophils from mastitis-affected cows. These results indicate that
\end{abstract}

\footnotetext{
Received June 30, 2004.

Accepted July 29, 2004.

Corresponding author: P. Boutet; e-mail: philippe.boutet@ ulg.ac.be.
}

neutrophil survival is enhanced in milk of subclinical mastitis-affected cows and suggest a role for a GMCSFactivated STAT5 signaling pathway in this phenomenon. This pathway could thus represent a target for the control of persistent accumulation of neutrophils in the bovine mammary gland.

(Key words: mastitis, apoptosis, granulocyte-macrophage colony-stimulating factor, signal transducer and activator of transcription)

Abbreviation key: GAPDH = glyceraldehyde-3phosphate dehydrogenase, RT-PCR = reverse transcription PCR, STAT = signal transducer and activator of transcription.

\section{INTRODUCTION}

Bovine subclinical mastitis can be defined as a moderated inflammatory disease resulting from an imbalance between the bacteria virulence and host defense mechanisms, which consequence is a fluctuating increase in SCC. This increase is mainly due to the migration of polymorphonuclear neutrophils that are essential components of the innate immunity. They form the first line of defense against bacterial infections. In the course of eliminating pathogens, neutrophils can also be detrimental to tissues by releasing intracellular products which exacerbate the inflammatory process resulting in damage to alveolar tissue, reduction in milk yield, and deterioration in milk composition (Murphy et al., 1989; Harmon, 1994; Klei et al., 1998).

Persistent accumulation of inflammatory cells at the inflammatory site requires both continuous neutrophil influx and increased survival of extravasated granulocytes. Indeed, delayed neutrophil apoptosis has been reported to be a general phenomenon contributing to the development of neutrophilia (Dibbert et al., 1999). Numerous inflammatory mediators are able to regulate the life span of neutrophils. However, it has been established that GMCSF crucially contributes to inhibition of granulocyte apoptosis at the site of inflammation (Brach et al., 1992; Colotta et al., 1992; Wei et 
al., 1996), and therefore may contribute to the accumulation of inflammatory cells at the site of inflammation.

Treatment of human neutrophils with GMCSF activates several tyrosine kinases including Jak2, a member of the Janus family of tyrosine kinases (Brizzi et al., 1996). Jak enzymes act upstream of a family of transcription factors referred to as signal transducers and activators of transcription (STAT) proteins (Kisseleva et al., 2002). Al-Shami et al. (1998) have reported that the stimulation of human neutrophils by GMCSF led to a specific activation profile of the Jak/ STAT pathway and only resulted in the tyrosine phosphorylation of Jak2 and of STAT3 and STAT5, suggesting that those members of the STAT family are implicated in antiapoptotic effects of GMCSF. It has been further confirmed that STAT5 is an essential factor in promoting GMCSF-dependent survival of differentiating myeloid progenitors, and that STAT5 exerts its antiapoptotic activity by inducing $\mathrm{Bcl}-\mathrm{x}_{\mathrm{L}}$ expression (Kieslinger et al., 2000). Bcl- $\mathrm{x}_{\mathrm{L}}$ is a member of the Bcl-2 family, which contains both antiapoptotic proteins such as Bcl-2, Bxl- $\mathrm{x}_{\mathrm{L}}$, and Mcl-1, and proapoptotic proteins such as Bax, Bad, and Bcl- $\mathrm{x}_{\mathrm{S}}$ (Reed, 1997; Simon, 2003). Moreover, increased levels of active STAT5 were found in broncho-alveolar lavage fluid granulocytes from heaves-affected horses, an animal model of asthma (Turlej et al., 2001). In this model, STAT5 activity was markedly reduced after treatment of broncho-alveolar lavage fluid neutrophils with antiGMCSF receptor antibodies.

As we previously found increased GMCSF levels in milk cells of mastitis-affected cows (Boulanger et al., 2003), we sought to determine whether GMCSF delays milk neutrophil apoptosis from cows with subclinical mastitis by activating a STAT signaling pathway. Moreover, because the GMCSF-mediated survival pathway appears to be linked to modifications in the expression level of Bcl-2 family members, we also investigated the potential role of Bax, Mcl-1, and Bcl- $\mathrm{x}_{\mathrm{L}}$ in the mammary gland inflammation. We first determined the involvement of this pathway in blood neutrophils and then we investigated its potential role in milk neutrophils.

\section{MATERIALS AND METHODS}

\section{Experimental Animals}

Healthy and subclinical mastitis-affected HolsteinFriesian cows were used in this study. Healthy cows had a low udder milk SCC $\left(<10^{5}\right.$ cell $\left.\mathrm{s} / \mathrm{mL}\right)$ and were free of any clinical sign of mastitis. Subclinical mastitis-affected cows had persistently increased SCC (at least 3 consecutive times $>4 \times 10^{5}$ cells $/ \mathrm{mL}$ ) as determined by monthly SCC measurements, but were de- void of any clinical sign of the disease. Experimental cows did not receive any treatment during the month preceding the experiments.

\section{Isolation of Blood and Milk Granulocytes}

Blood samples from healthy and subclinical mastitis-affected cows were collected in heparinized tubes. Granulocytes were isolated by density centrifugation using the Histopaque gradient technique (specific gravity 1.077; Sigma, Bornem, Belgium). Contaminating erythrocytes were removed from the granulocyte fraction by hypotonic lysis. Granulocyte purity, as determined by counting of cytospin preparations stained with May-Grundwald Giemsa (VWR, Leuven, Belgium), was always greater than $95 \%$. Cows with eosinophil counts greater than $10 \%$ were excluded. Cell density was assessed by the use of a hemacytometer.

Milk from healthy and subclinical mastitis-affected cows was always obtained at the morning milking from one quarter. Quarter milk samples were first filtered with 70- $\mu \mathrm{m}$ cell strainers (Becton Dickinson, Erembodegem-Aalst, Belgium) to discard filths. Somatic cell counts were performed using a DeLaval cell counter DCC (DeLaval N.V., Drongen, Belgium). A control sample was performed with a Fossomatic Automatic Cell Counter (Foss Electric, Hillerød, Denmark). Then, samples were centrifuged $(300 \times g)$ for $15 \mathrm{~min}$ at $4^{\circ} \mathrm{C}$. The fat was removed, the supernatant was discarded, and the tubes were kept upside down until they were carefully cleaned with a paper swab to remove fat adhering to the tube wall. The pelleted cells were finally resuspended in PBS. Granulocytes from healthy cows were purified by density centrifugation as described above. Milk granulocyte purity was always greater than $90 \%$.

\section{Culture and Treatment of Granulocytes}

Blood and milk neutrophils were cultured at $2 \times$ $106 / \mathrm{mL}$ in RPMI 1640 medium supplemented with $1 \%$ glutamine, $10 \%$ fetal calf serum, $50 \mu \mathrm{g} / \mathrm{mL}$ streptomycin, and $50 \mathrm{IU} / \mathrm{mL}$ penicillin (all from Gibco Invitrogen, Merelbeke, Belgium). Cells were incubated at $37^{\circ} \mathrm{C}$ and cultured in the presence or absence of $100 \mathrm{U} / \mathrm{mL}$ human GMCSF (10 ng/mL; Roche Diagnostics, Brussels, Belgium) and/or tyrphostin AG-490 (Sigma Aldrich, Bornem, Belgium) for different times before analyses. Previous experiments showed a dose-dependent antiapoptotic response to GMCSF that was significantly different from control values at $100 \mathrm{U} / \mathrm{mL}$. In blood neutrophils, AG-490 was added $1 \mathrm{~h}$ before GMCSF treatment. As a control, neutrophils were also cultured with ethyl alcohol absolute (VWR, Leuven Belgium), used as AG-490 solvent (data not shown). 


\section{Apoptosis Assays}

Apoptosis was assessed by staining with annexinV-fluorescein and propidium iodide using the AnnexinV-FLUOS staining kit (Roche, Mannheim, Germany) following the recommendations of the manufacturer. Flow cytometry analyses were assessed with a FACStar Plus (Becton Dickinson, San Jose, CA). All experiments were performed in duplicate.

\section{Protein Extraction}

Protein extracts were prepared as previously described by Al-Shami et al. (1998), with some modifications. Isolated neutrophils were centrifuged for $10 \mathrm{~min}$ at $300 \times g$ and the pellet was resuspended in $600 \mu \mathrm{L}$ of lysis buffer $(0.1 \%$ Nonidet P- $40 ; 10 \mathrm{mM}$ Tris $\mathrm{HCl}$, pH 7.4; $10 \mathrm{~m} M$ NaCl; $3 \mathrm{~m} M \mathrm{MgCl}_{2} ; 1 \mathrm{~m} M$ EDTA; 2 $\mathrm{m} M$ sodium orthovanadate; $1 \mathrm{~m} M$ diisopropyl fluorophosphates (Sigma); $10 \mu \mathrm{g} / \mathrm{mL}$ leupeptin; $10 \mu \mathrm{g} / \mathrm{mL}$ aprotinin). The cells were vortexed $15 \mathrm{~s}$, kept on ice for $5 \mathrm{~min}$, and centrifuged for $10 \mathrm{~min}$ at $300 \times g$. The resulting pellet was resuspended in a $\mathrm{KCl}$ buffer $(10$ $\mathrm{m} M$ HEPES, $\mathrm{pH}$ 7.4; $400 \mathrm{~m} M \mathrm{KCl} ; 10 \%$ glycerol; 2 $\mathrm{m} M$ EDTA; $1 \mathrm{~m} M$ ethylene glycol-bis[beta-aminoethyl ether]-N,N, $\mathrm{N}^{\prime} \mathrm{N}^{\prime}$-tetraacetic acid; $1 \%$ Nonidet P-40, 1 $\mathrm{m} M$ dithiothreitol; $2 \mathrm{~m} M$ sodium orthovanadate; $10 \mu \mathrm{g} /$ $\mathrm{mL}$ leupeptin; $10 \mu \mathrm{g} / \mathrm{mL}$ aprotinin; $1 \mathrm{~m} M$ diisopropyl fluorophosphates) and kept at $4^{\circ} \mathrm{C}$ for $10 \mathrm{~min}$ before centrifugation for $15 \mathrm{~min}$ at $12,000 \times \mathrm{g}$. The supernatant was stored at $-80^{\circ} \mathrm{C}$ until use. Protein amounts were quantified using the Biorad Dc Protein Assay (Lowry method; Biorad, Nazareth, Belgium).

\section{Electrophoretic Mobility Shift Assays}

Binding reactions were performed for $30 \mathrm{~min}$ at room temperature with $5 \mu \mathrm{g}$ of total protein extracts in 20 $\mathrm{m} M$ HEPES (pH 7.9), $10 \mathrm{~m} M \mathrm{KCl}, 0.2 \mathrm{~m} M$ EDTA, $20 \%$ (vol/vol) glycerol, $1 \%$ (wt/vol) acetylated BSA, $3 \mu \mathrm{g}$ of poly(dI-dC) (Amersham Biosciences, Roosendaal, Netherlands), $1 \mathrm{~m} M$ dithiothreitol, $1 \mathrm{~m} M$ phenylmethylsulfonyl fluoride, and 100,000 cpm of ${ }^{32}$ P-labeled double-stranded oligonucleotide probes. Probes were prepared by annealing the appropriate singlestranded oligonucleotides (Eurogentec, Liège, Belgium) at $65^{\circ} \mathrm{C}$ for $10 \mathrm{~min}$ in $10 \mathrm{mM}$ Tris, $1 \mathrm{mM}$ EDTA, and $10 \mathrm{mM} \mathrm{NaCl}$, followed by slow cooling to room temperature. The probes were labeled by end-filling with the Klenow fragment of Escherichia coli DNA polymerase I (Roche, Mannheim, Germany), with $\left[{ }^{32} \mathrm{P}\right] \mathrm{dATP}$ and $\left[{ }^{32} \mathrm{P}\right] \mathrm{dCTP}$ (Dupont-New England Nuclear, Les Ulis, France). Labeled probes were purified by spin chromatography on Sephadex G-25 columns (Roche). DNA-protein complexes were separated from unbound probe on $4 \%$ native polyacrylamide gels at $150 \mathrm{~V}$ in $0.25 M$ Tris, $0.25 M$ sodium borate, and 0.5 $\mathrm{m} M$ EDTA, $\mathrm{pH}$ 8.0. Gels were vacuum-dried and exposed to Fuji x-ray film (Tokyo, Japan) at $-80^{\circ} \mathrm{C}$ for $12 \mathrm{~h}$. To confirm specificity, competition assays were performed with a 50-fold excess of unlabeled wildtype and mutated probes. For supershift experiments, 1.5 $\mu \mathrm{L}$ of each antibody were incubated with the extracts 30 min before addition of the radiolabeled probe. The sequences of the oligonucleotides used in this work were as follows: wildtype STAT5 probe, the 21-bp GASlike element from the promoter of the bovine $\beta$-casein (Gouilleux et al., 1995), 5'-AGATTTCTAGGAATTCA AATC-3'; mutated STAT5 probe, 5'-AGATTTCTAAT CGTTCAAATC-3'; STAT3, 5'-GATCCTTCTGGGAAT TCCTA-3'. Binding of the noninducible transcription factor OCT-1 was used as an internal standard (data not shown). The OCT-1 probe was as follows: 5'TGTCGAATGCAAATCACTAGAA-3'.

\section{Immunoblots}

Protein extracts $(10 \mu \mathrm{g})$ were added to a loading buffer (10 mM Tris-HCl (pH 6.8), 1\% (wt/vol) SDS, $25 \%$ (vol/vol) glycerol, $0.1 \mathrm{mM}$ 2-mercaptoethanol, and $0.03 \%$ (wt/vol) bromophenol blue), boiled, and run on a 10\% SDS-PAGE gel. After electrotransfer to polyvinylidene difluoride membranes (Roche) and blocking overnight at $4^{\circ} \mathrm{C}$ with $20 \mathrm{~m} M$ Tris (pH 7.5), $500 \mathrm{mM}$ $\mathrm{NaCl}, 0.2$ (vol/vol) Tween 20 (Tris-HCl/ Tween), and $5 \%$ (wt/vol) dry milk, the membranes were incubated for $1 \mathrm{~h}$ with primary antibodies directed to GMCSF (1/200 dilution), washed, and then incubated for 45 min with peroxidase-conjugated rabbit antimouse IgG (1/1000 dilution). Resulting reactions were revealed with the enhanced chemiluminescence detection method (ECL kit; Amersham Biosciences). The relative expression levels of GMCSF were determined by photodensitometry of the specific bands (Gel Doc 2000; Bio-Rad, Hercules, CA). Equal loading of proteins on the gels was confirmed by performing silver stains (data not shown).

\section{Anti-STAT1, AntiSTAT3, AntiSTAT5, AntiOCT1, and AntiGMCSF Antibodies}

Anti-STAT antibodies used were: (1) a mouse monoclonal antibody recognizing human STAT1 p84/p91 (C136; Santa Cruz Biotechnology, Inc., Santa Cruz, California); (2) a mouse monoclonal antibody recognizing human STAT3 (F-2; Santa Cruz Biotechnology, Inc.); and (3) a rabbit polyclonal antibody recognizing human STAT5a and STAT5b at the N-terminus (N-20; Santa Cruz Biotechnology, Inc.). The antiOCT1 anti- 
body used was a rabbit polyclonal antibody recognizing human OCT1 (C-21; Santa Cruz Biotechnology, Inc.). The antiGMCSF antibody used was a mouse monoclonal antibody recognizing bovine GMCSF (CC305; Serotec, Ltd., Oxford, UK).

\section{Reverse Transcription-Polymerase Chain Reactions}

Total RNA was extracted from cells using the Rneasy Mini kit according to manufacturer's instructions (Qiagen, Hilden, Germany). Poly(A) RNA was primed with oligo(dT) (Roche) and reverse transcribed with AMV reverse transcription (Roche) for $1 \mathrm{~h}$ at $42^{\circ} \mathrm{C}$. cDNA products were amplified by PCR using primers specific for Bax (5'-AGGATGATTGCCGCCG TGG-3' and 5'-CAGTTGAAGTTGCCGTCAGA-3'; L22473), Mcl-1 (5'-CAACCACGAGACGGCCTTCCA$3^{\prime}$ and 5'-AGCAACACCTGCAAAAGCCAGC-3'; AF118124), bcl- $\mathrm{x}_{\mathrm{L}}$ (5'-ATGGCAGCAGTAAAGCAAG$3^{\prime}$ and 5'-GCTGCATTGTTCCCATAGA-3'; BT007208) and glyceraldehydes-3-phosphate dehydrogenase (GAPDH) as a control (5'-GAGATGATGACCCTTTTG GC-3' and 5'-GTGAAGGTCGGAGTCAACG-3'; P00354). All primers were purchased from Eurogentec. A $50-\mu \mathrm{L}$ PCR reaction was set up containing $5 \mu \mathrm{L}$ of cDNA, $10 \mathrm{~m} M$ Tris-HCl, 25 pmol of each primer, 1.5 $\mathrm{mM} \mathrm{MgCl} 2,0.2 \mathrm{mM} \mathrm{dNTP}$, and $2.5 \mathrm{U}$ of AmpliTaq DNA polymerase (Perkin Elmer, Boston, MA). Amplification consisted of 35 (Bax), 23 (Mcl-1), or $30\left(\right.$ Bcl- $\mathrm{x}_{\mathrm{L}}$ ) cycles of denaturation at $94^{\circ} \mathrm{C}$ for $30 \mathrm{~s}$, annealing at $57^{\circ} \mathrm{C}$ (Bax), $63^{\circ} \mathrm{C}(\mathrm{Mcl}-1)$, or $51^{\circ} \mathrm{C}\left(\mathrm{Bcl}-\mathrm{x}_{\mathrm{L}}\right)$ for $30 \mathrm{~s}$, and extension at $72^{\circ} \mathrm{C}$ for $1 \mathrm{~min}$. Amplification products were electrophoresed on 1.5\% agarose gels, and PCR product quantities were assessed by densitometry (Gel Doc 2000; Bio-Rad).

\section{Statistical Analysis}

Data are presented as means \pm standard deviations (SD). The differences between mean values were estimated by use of Student's $t$-tests for unpaired data. For GMCSF expression levels, an ANOVA with subsequent Fisher's protected least significant difference test was used. $P<0.05$ was considered as significant.

\section{RESULTS}

\section{GMCSF Prevents Apoptosis and Induces Activation of STAT5 with Up-Regulation of Bcl- $x_{L}$ mRNA in Bovine Blood Neutrophils}

If many studies have demonstrated that GMCSF delays the apoptotic cell death of human neutrophil, the question of whether GMCSF prevents the
A
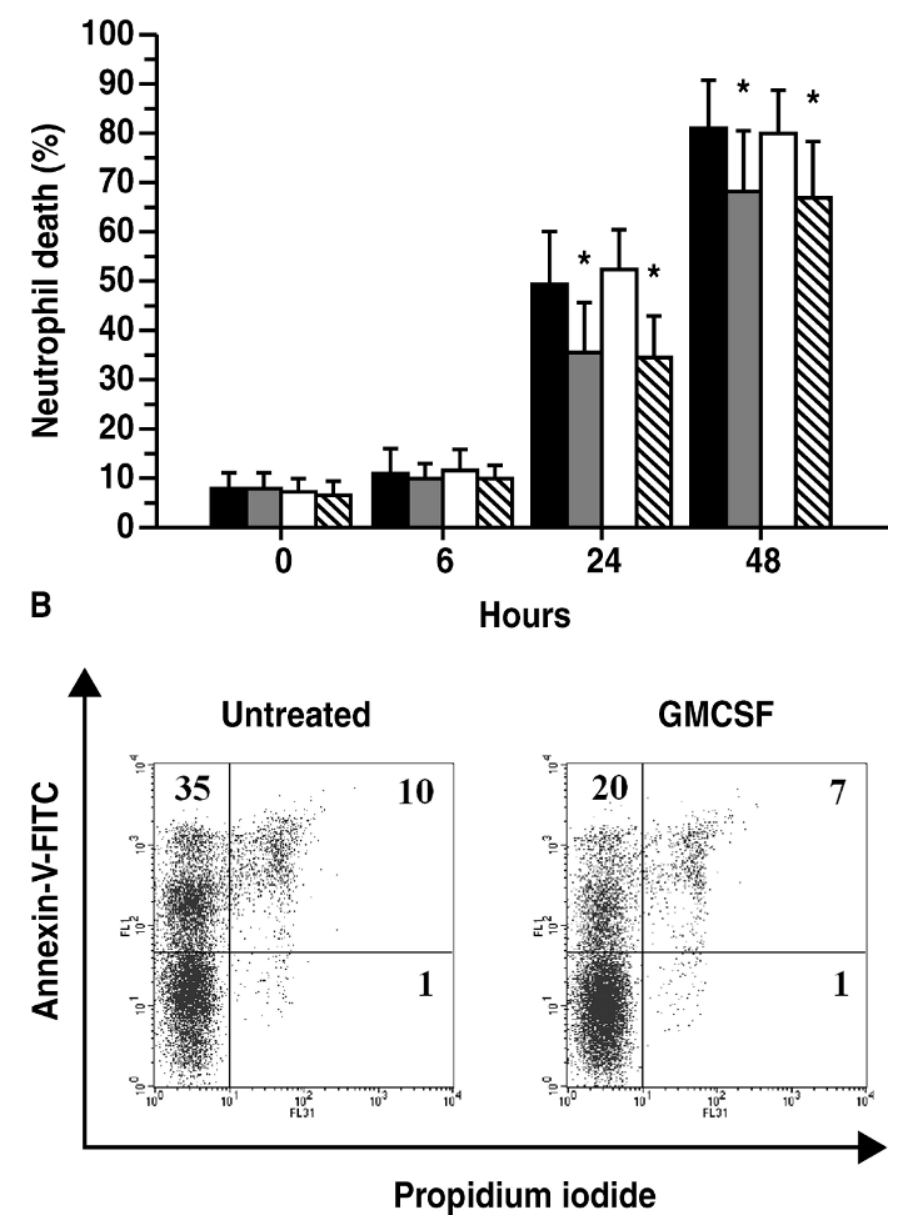

Figure 1. Granulocyte-macrophage colony-stimulating factor delays bovine neutrophil apoptosis. (A) Kinetic analysis of apoptosis in blood neutrophils from healthy (solid: untreated; gray: treated) and subclinical mastitis-affected cows (open: untreated; hatched: treated). Data are presented as means \pm SD $(n=6)$. *Significantly different from values obtained with untreated cells. (B) Representative flow cytometry analysis using dual color annexin-V-fluorescein (FITC) and propidium iodide staining at $24 \mathrm{~h}$. The percentage of single- or doublepositive healthy neutrophils in individual quadrants is shown.

apoptosis of bovine neutrophil has never been addressed. To solve this issue, blood neutrophils from healthy and subclinical mastitis-affected cows were cultured in the presence or absence of GMCSF for 6 , 24 , and $48 \mathrm{~h}$ before apoptosis and necrosis detection using dual color annexin-V-fluorescein/propidium iodide staining and flow cytometry analyses. From 24 h, GMCSF-stimulated blood neutrophils from both healthy and mastitis-affected cows showed a similar significant apoptosis delay compared with untreated cells (Figure 1).

To investigate the potential involvement of the STAT family in the mechanism of GMCSF-induced neutrophil survival, blood neutrophils of healthy cows 
$\mathbf{A}$
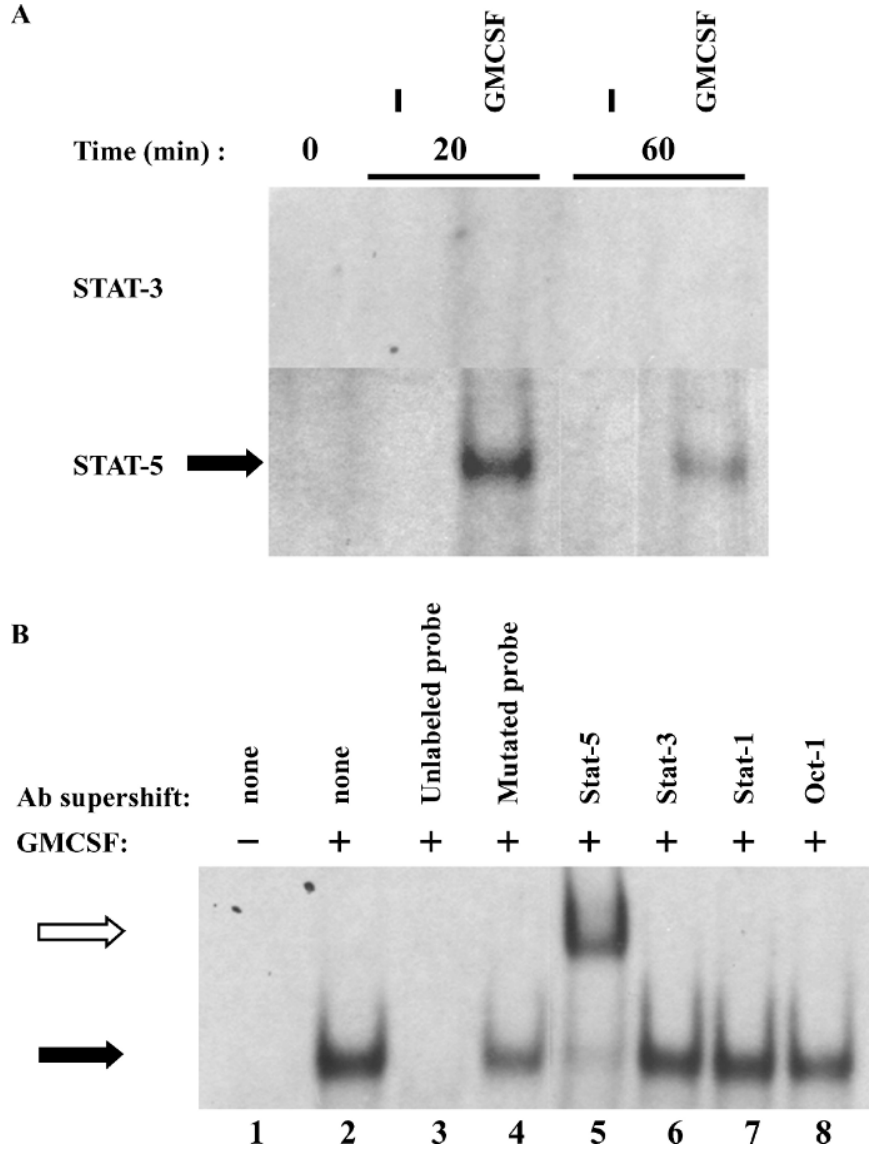

Figure 2. Activation of STAT5 in bovine blood neutrophils by GMCSF. (A) STAT3 and STAT5 DNA-binding activity by electrophoretic mobility shift assay performed 20 and 60 min after GMCSF treatment. (B) Specificity of STAT5 complexes was confirmed by competition experiments using the same nuclear extracts incubated with a 50-fold excess unlabelled wildtype (lane 3 ) and mutated probes (lane 4) and by supershift analysis using antibodies directed against members of the STAT family (lanes 5 to 7 ) and OCT-1 (lane 8). Specific STAT complexes are indicated by solid arrows. The supershift band is indicated by an open arrow. These results are representative of at least 3 similar experiments.

were stimulated with GMCSF and protein extracts were analyzed by electrophoretic mobility shift assay for STAT3 and STAT5 DNA-binding activity (Figure 2A). Active STAT5 complexes were detected $20 \mathrm{~min}$ after stimulation. This activity was still detectable at 60 min but declined. No active STAT3 complex was detected. DNA-binding competition experiments using 50 -fold excess of unlabelled wildtype and mutated STAT5 probes confirmed specificity of STAT5 binding activity (Figure 2B, lanes 3 and 4). Moreover, supershift experiments were performed with antibodies directed against members of the STAT family, STAT1, STAT3, and STAT5 (Figure 2B, lanes 5 to 7). Only STAT5 antibodies directed against both STAT5a and STAT5b proteins were able to supershift the complex
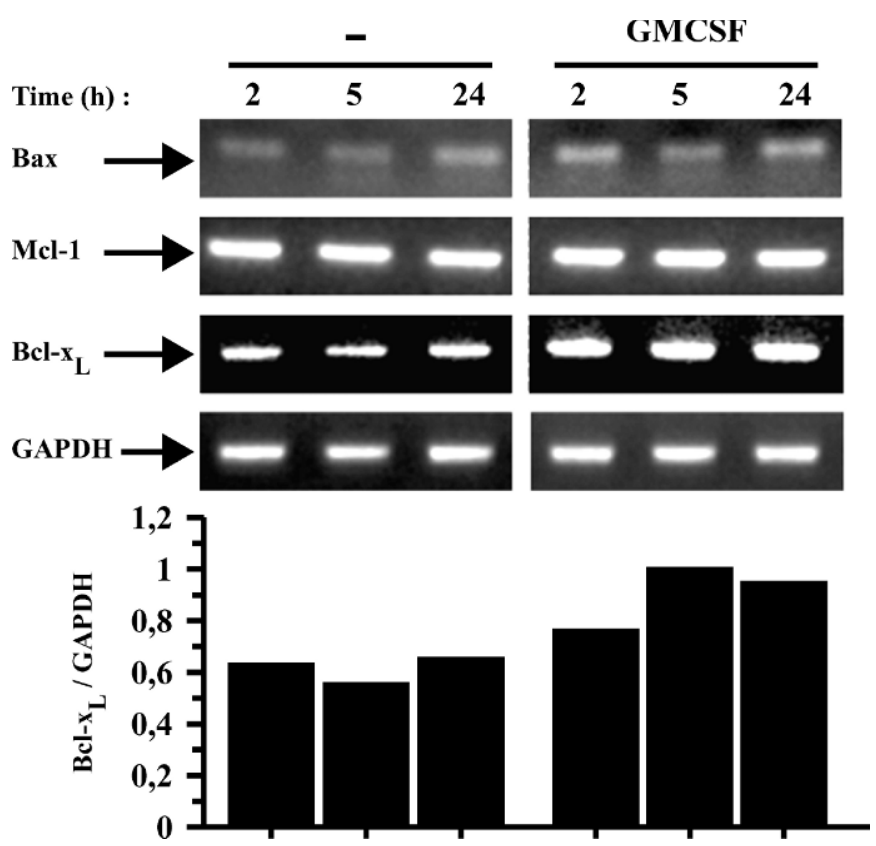

Figure 3. Induction of Bcl- $x_{L}$ mRNA up-regulation in bovine blood neutrophils by GMCSF. RNA was prepared from healthy blood neutrophils cultured for 2,5 , and $24 \mathrm{~h}$ with or without GMCSF and analyzed by reverse transcription-PCR for expression of Bax, Mcl-1, and Bcl- $\mathrm{x}_{\mathrm{L}}$. As a control for quantification, glyceraldehyde-3-phosphate dehydrogenase (GAPDH) was also amplified. Filled columns show the ratio between Bcl- $\mathrm{x}_{\mathrm{L}}$ and GAPDH mRNA, as determined by densitometry analyses. These results are representative of at least 3 comparable experiments.

(Figure 2B, lane 5) confirming that STAT5 proteins were present in the shifted complex.

Apoptosis is tightly regulated by the Bcl-2 family of proteins, which consists of members with either antiapoptotic or proapoptotic function (Adams and Cory, 1998). To determine whether GMCSF mediates bovine neutrophil survival activity through the control of Bcl2 members, levels of mRNA expression of 3 representative members of this family, namely Bax, Mcl-1, and Bcl- $\mathrm{x}_{\mathrm{L}}$, were assessed by semiquantitative reverse transcription PCR (RT-PCR) in untreated and GMCSF-treated blood neutrophils for 2, 5, and $24 \mathrm{~h}$. As shown in Figure 3, Bax and Mcl-1 mRNA levels remained constant throughout the protocol in both treated and untreated cells. In contrast, Bcl- $\mathrm{x}_{\mathrm{L}}$ levels were increased after GMCSF stimulation.

These results demonstrate that GMCSF (1) delays bovine neutrophil apoptosis, (2) leads to the activation of STAT5, and (3) induces an increase in the mRNA of the antiapoptotic Bcl-2 family member, Bcl- $\mathrm{x}_{\mathrm{L}}$.

\section{Reversal of GMCSF AntiApoptotic Activity by AG-490 in Blood Neutrophils}

The role of STAT5 activation in GMCSF-mediated delay in apoptosis and in Bcl- $\mathrm{x}_{\mathrm{L}}$ mRNA up-regulation 
was evaluated using the Jak-selective tyrphostin pharmacologic inhibitor, AG-490 (Levitzki, 1999). AG490 was demonstrated to be a selective inhibitor of Jak2 and Jak3 and thereby reduces STAT activation (Kirken et al., 1999). As active STAT5 complexes were detected in protein extracts of GMCSF-treated neutrophils, increasing doses of AG-490 were used to determine the appropriate STAT5 inhibiting dose (Figure 4). We found that STAT5 DNA-binding activity was attenuated by doses of 50 and $100 \mu M$ (Figure 4A, lanes 7 and 8) and completely inhibited by a dose of $200 \mu M$ (Figure 4A, lane 9). To confirm the role of STAT5 activation in Bcl- $\mathrm{x}_{\mathrm{L}}$ expression, healthy blood neutrophils were treated with GMCSF alone or in combination with a dose of $200 \mu M$ AG-490, and RT-PCR was performed (Figure 4B). We observed that GMCSFdependent up-regulation of $\mathrm{Bcl}-\mathrm{x}_{\mathrm{L}}$ mRNA was blocked by the Jak inhibitor, AG-490.

Finally, blood neutrophils from healthy and subclinical mastitis-affected cows were exposed to GMCSF in the presence of AG-490 and apoptosis assays were performed (Figure 5). Apoptosis rates were compared with those in untreated and GMCSF-treated cells from the same donor. We found that AG-490 treatment prevented the GMCSF-mediated protection from apoptosis in neutrophils from both healthy and mastitis-affected cows. At 24 and $48 \mathrm{~h}$, the amounts of apoptosis in cultured cells and in AG-490-treated cells were similar and statistically higher than those from GMCSF-treated neutrophils. In all cases, cell death was due to apoptosis, rather than necrosis. These observations suggest the involvement of STAT5 in GMCSF-mediated delay of neutrophil apoptosis.

\section{GMCSF Expression Level in Milk Cells from Cows with Subclinical Mastitis Varies According to SCC}

Our laboratory has previously demonstrated that the expression level of GMCSF in milk cells from chronic mastitis-affected cows varied from low to high (Boulanger et al., 2003). However, the question of whether GMCSF expression level varies with SCC has never been addressed. Protein extracts obtained from milk cells of 5 healthy and 12 subclinical mastitisaffected cows were used to measure GMCSF levels by immunoblot and photodensitometry analysis (Figure 6 ). According to the SCC measured at sampling time, mastitis-affected cows were categorized into 3 groups: group $1(\mathrm{n}=4), 4 \times 10^{5} \leq \mathrm{SCC}<10^{6}$; group $2(\mathrm{n}=5)$, $10^{6} \leq \mathrm{SCC}<2 \times 10^{6}$; group $3(\mathrm{n}=3), \mathrm{SCC} \geq 2 \times 10^{6}$ cells/mL. Granulocyte-macrophage colony-stimulating factor levels were compared with those found in healthy milk (Figure 6B). Granulocyte-macrophage colony-stimulating factor expression was approxi-
A

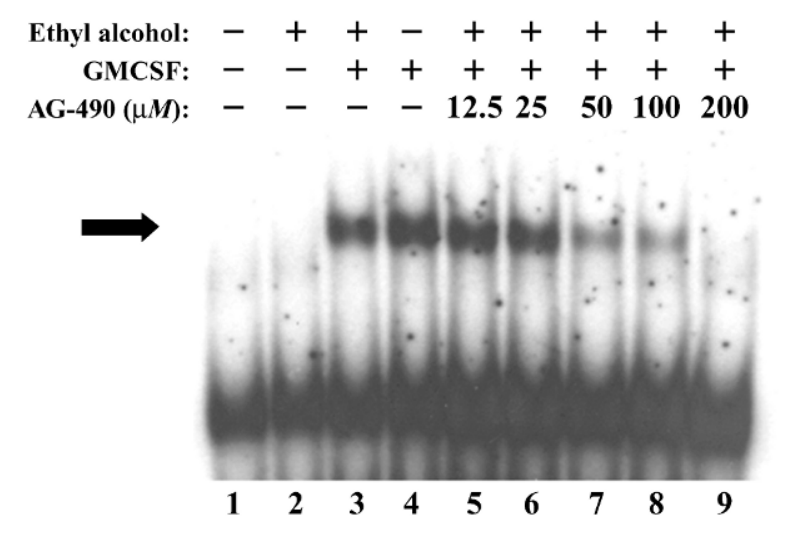

B
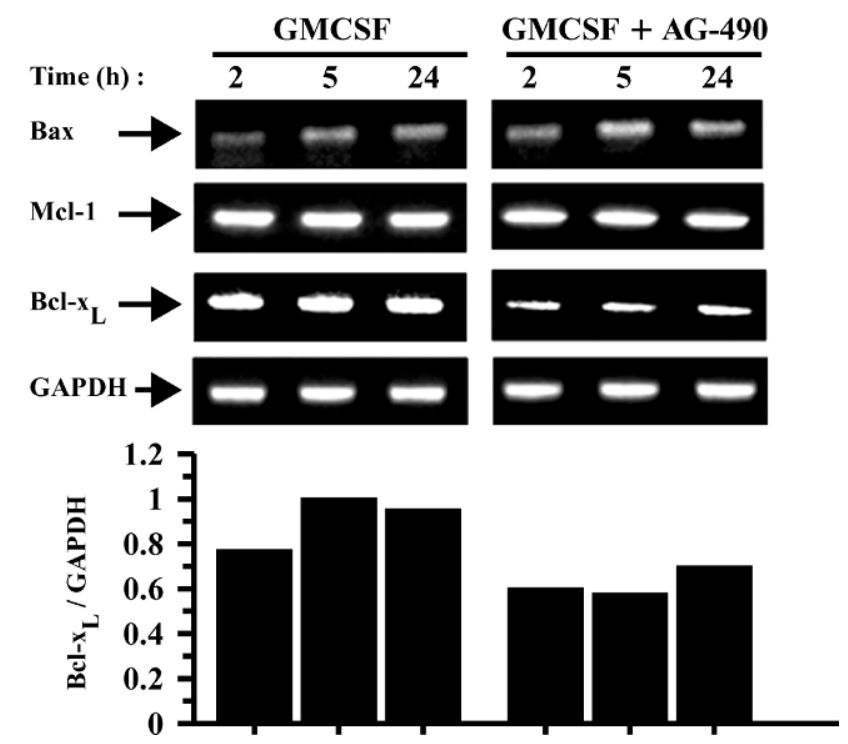

Figure 4. Activation by GMCSF of STAT5 and up-regulation of Bcl- $x_{L}$ mRNA blocked by AG-490. (A) Healthy blood neutrophils were treated for $1 \mathrm{~h}$ with medium (lane 1) and drug solvent alone (ethyl alcohol absolute, vehicle control) (lane 2) or with the indicated concentrations of AG-490 (lanes 5 to 9). Cells were then stimulated with GMCSF for 20 min before protein extraction was performed and STAT5 DNA-binding activity analyzed by electrophoretic mobility shift assay. (B) RNA was prepared from healthy blood neutrophils cultured in the presence or absence of AG-490 $(200 \mu M)$ and then stimulated with GMCSF. Expression of Bax, Mcl-1, and Bcl- $\mathrm{x}_{\mathrm{L}}$ were performed by reverse transcription-PCR. As a control for quantification, glyceraldehyde-3-phosphate dehydrogenase (GAPDH) was also amplified. Filled columns show the ratio between Bcl- $\mathrm{x}_{\mathrm{L}}$ and GAPDH mRNA, as determined by densitometry analyses. These results are representative of at least 3 comparable experiments.

mately 4-fold higher in group 1, 7-fold higher in group 2 , and 9-fold higher in group 3 . These results demonstrate that GMCSF expression level in milk cells from subclinical mastitis-affected cows varies according to SCC. 

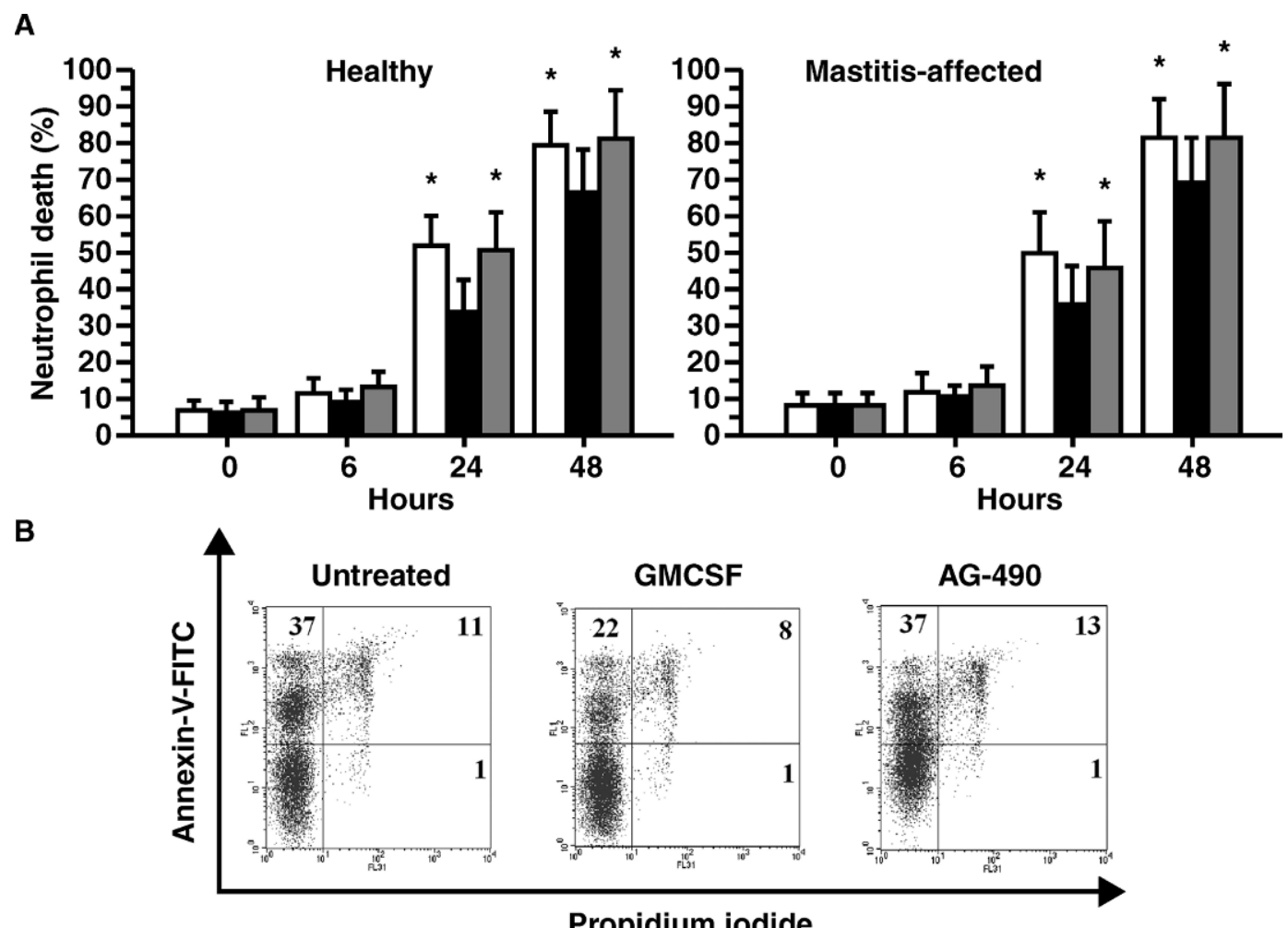

Propidium iodide

Figure 5. Reversal of GMCSF antiapoptotic activity by AG-490 in blood neutrophils. (A) Cells from healthy (left) and subclinical mastitisaffected cows (right) were cultured in the absence (open) or presence (solid) of GMCSF, or with a combination of GMCSF and AG-490 (200 $\mu M)$ (gray). Results are presented as means $\pm \mathrm{SD}(\mathrm{n}=6)$. *Significantly different from values obtained with GMCSF-treated cells. (B) Representative flow cytometry analysis using dual color annexin-V-fluorescein (FITC) and propidium iodide staining at $24 \mathrm{~h}$. The percentage of single- or double-positive healthy neutrophils in individual quadrants is shown.

\section{Milk Neutrophils from Subclinical Mastitis-Affected Cows Present a Significant Delay in Apoptosis}

To determine whether subclinical mastitis is associated with an increase in milk neutrophil survival, milk cells from healthy and subclinical mastitis-affected cows with SCC higher than $10^{6}$ cells $/ \mathrm{mL}$ were cultured for different times before apoptosis assays (Figure 7). At $0 \mathrm{~h}$, when the rate of spontaneous apoptosis was $74.3 \%$ in neutrophils of healthy cows, the rate of neutrophils of mastitis-affected cows was $19.7 \%$. After 24 h, neutrophil apoptosis of healthy cows reached $97.9 \%$, whereas the rate of neutrophils from affected cows was $44.8 \%$. Then, to establish the involvement of GMCSF in enhanced survival of milk neutrophils from subclinical mastitis-affected cows, these cells were cultured in the presence or absence of GMCSF (Figure 7). Moreover, apoptosis rates were compared with those of blood neutrophils. At the different times tested, apoptosis levels of GMCSF-treated and untreated milk neutrophils were comparable. Interestingly, whereas milk cells apoptosis was significantly higher than those of blood neutrophils at $0 \mathrm{~h}$ and $6 \mathrm{~h}$, apoptosis rates of milk neutrophils at 24 at $48 \mathrm{~h}$ were then similar to those of GMCSF-treated blood neutrophils.

These results indicate that (1) antiapoptotic mechanisms enhance the survival of neutrophils that have migrated from blood to udder of subclinical mastitisaffected cows, and that (2) these cells are unresponsive to GMCSF stimulation, suggesting that they are maximally stimulated by GMCSF at the site of inflammation.

\section{STAT5 Activity Profile in Milk Cells}

We found that GMCSF activated STAT5 in bovine blood neutrophils and that the level of GMCSF expression in milk cells from subclinical mastitis-affected cows increased as SCC rose. We thus hypothesized that STAT5 might be activated in milk cells from mastitis affected-cows with an activity varying according to SCC. Protein extracts prepared from milk cells of 25 cows with different SCC were tested for STAT5 DNA-binding activity (Figure 8). No active STAT5 complex was detected in milk cells from healthy cows (Figure 8, lanes 1 to 3 ). However, STAT5 activity and 
A

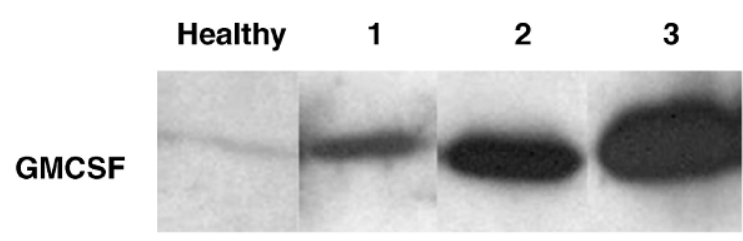

B

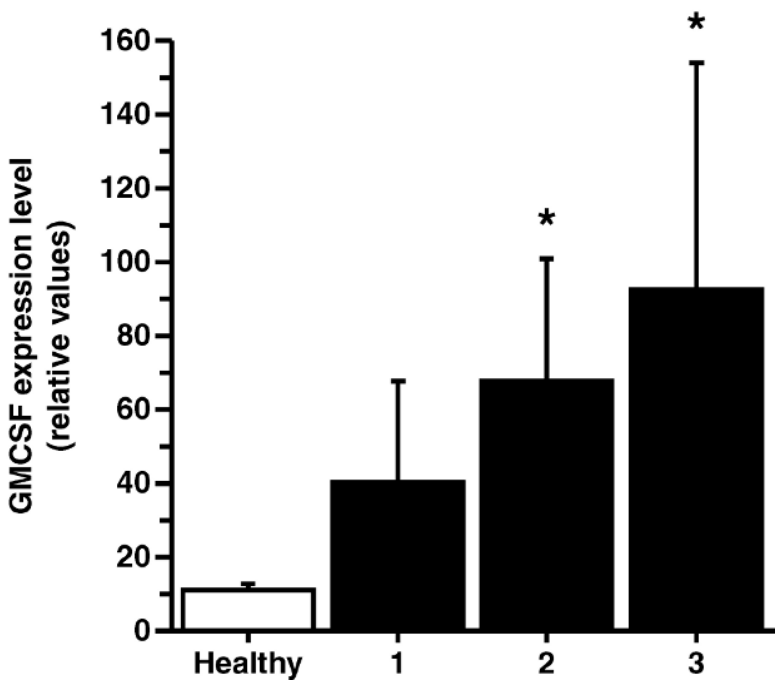

Figure 6. Expression level of GMCSF in milk cells from healthy and subclinical mastitis-affected cows according to SCC: (1) $4 \times 10^{5}$ $\leq \mathrm{SCC}<10^{6}(\mathrm{n}=4) ;(2) 10^{6} \leq \mathrm{SCC}<2 \times 10^{6}(\mathrm{n}=5) ;(3) \mathrm{SCC} \geq 2 \times$ $10^{6}$ cells $/ \mathrm{mL}(\mathrm{n}=3)$. (A) Representative GMCSF immunoblot performed with protein extracts from milk cells. (B) Expression level of GMCSF quantified by photodensitometry. *Significantly different from healthy level.

SCC simultaneously increased in milk from subclinical mastitis-affected cows (Figure 8, lanes 4 to 9). Microscopic analyses confirmed that neutrophils were the predominant cell type with percentages increasing as SCC rose (data not shown). These findings suggest that STAT5 activity appears to be related to SCC and to the number of neutrophils in milk.

\section{AG-490 Induces Apoptosis in Mastitis Milk Neutrophils with a Down-Regulation of $\mathrm{Bcl}-\mathrm{x}_{\mathrm{L}}$ mRNA}

To investigate the potential role of STAT5 in the apoptosis delay of neutrophils observed in milk from subclinical mastitis-affected cows, neutrophils from milk with SCC higher than $10^{6}$ cells $/ \mathrm{mL}$ were cultured in the presence or absence of AG-490 for different times before apoptosis assays (Figure 9A). We found that the inhibitor was able to induce apoptosis. From $24 \mathrm{~h}$, the apoptosis rate of AG-490-treated neutrophils was significantly higher than the rate of untreated cells. RT-PCR showed that Bax and Mcl-1 mRNA levels were
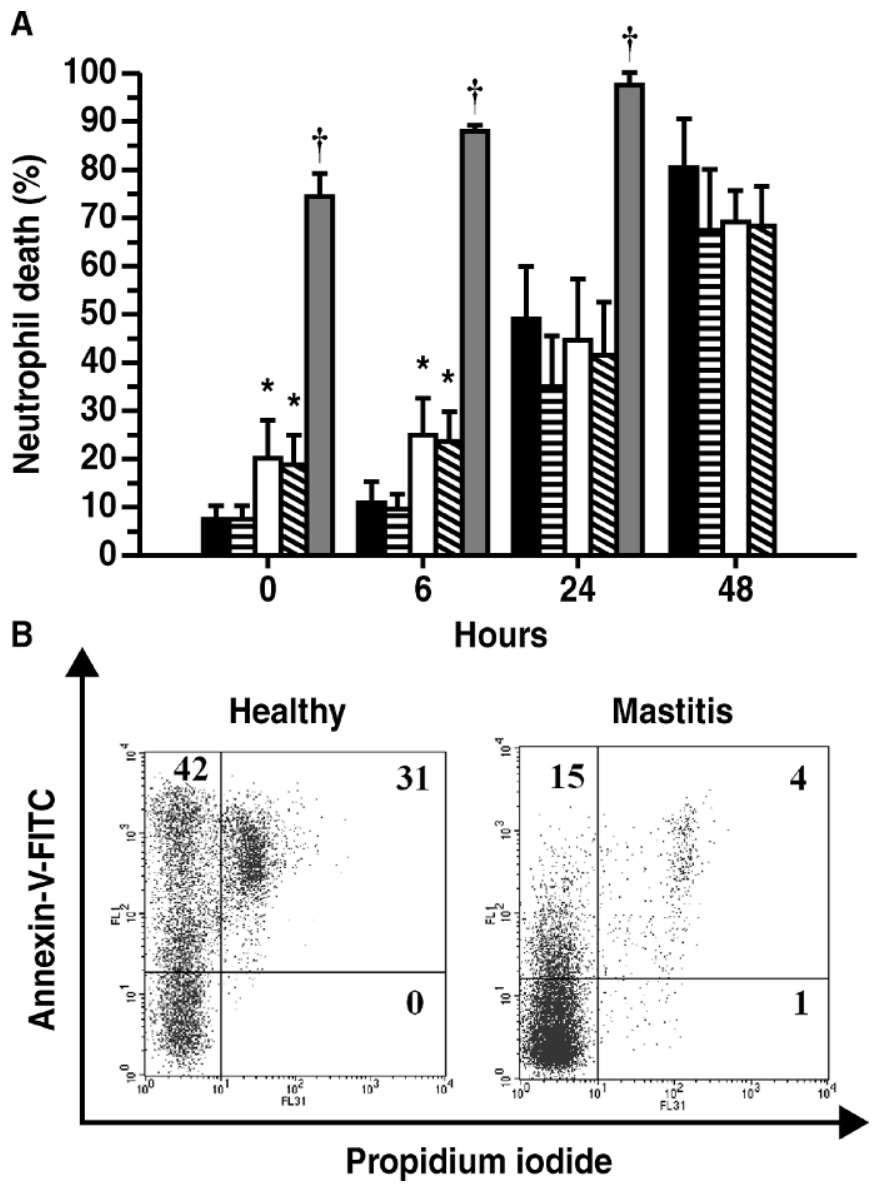

Figure 7. Apoptosis assays in milk neutrophils. (A) Kinetic analysis of apoptosis in milk neutrophils from healthy (gray) and subclinical mastitis-affected cows. Cells from mastitis cows were cultured in the presence or absence of GMCSF (open: untreated; hatched: treated). Apoptosis rates from healthy blood neutrophils (solid: untreated; horizontal line: treated) are represented as a comparison. Data are presented as means $\pm \mathrm{SD}(\mathrm{n}=6)$. ${ }^{\dagger}$ Significantly different from values obtained with milk neutrophils from subclinical mastitisaffected cows. *Significantly different from values obtained with GMCSF-treated blood neutrophils. (B) Representative flow cytometry analysis using dual color annexin-V-fluorescein (FITC) and propidium iodide staining at $0 \mathrm{~h}$. The percentage of single- or double-positive cells in individual quadrants is shown.

maintained in both treated and untreated cells (Figure 9C). By contrast, Bcl- $\mathrm{x}_{\mathrm{L}}$ mRNA was decreased $2 \mathrm{~h}$ after treatment and was almost completely down-regulated at $5 \mathrm{~h}$. These results suggest that STAT5 may be implicated in the antiapoptotic effect of GMCSF in milk neutrophils from subclinical mastitis-affected cows.

\section{DISCUSSION}

Persistent accumulation of neutrophils in the udder is a characteristic feature of subclinical and chronic mastitis in dairy cows. In many bacterial inflammatory diseases, delayed apoptosis is an important mech- 


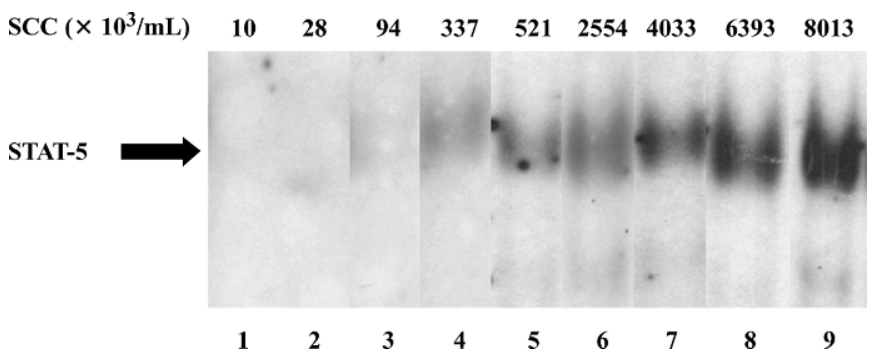

Figure 8. Activity of STAT5 in milk cells. Representative electrophoretic mobility shift assay performed with protein extracts prepared from milk cells of healthy cows (lanes 1 to 3 ) and subclinical mastitis-affected cows (lanes 4 to 9 ). The arrow indicates specific STAT5 complexes.

anism for neutrophil accumulation. Therefore, a reduction in inflammatory cell apoptosis is a central concept in the maintenance of inflammation and a potential target in the resolution of inflammation (Haslett, 1999). In the present study, we have demonstrated for the first time that an antiapoptotic mechanism enhances the survival of milk neutrophils from subclinical mastitis-affected cows, which could be implicated in the persistent accumulation of these cells in the udder. We suggest a role for a GMCSF-activated STAT5 signaling pathway in this phenomenon.

Delayed neutrophil apoptosis has been associated with several acute and chronic inflammatory diseases and appears to be largely mediated by excessive production of GMCSF (Saba et al., 2002; Garlichs et al., 2004). We found that GMCSF expression was increased in milk cells from subclinical mastitis-affected cows and that levels were higher as SCC increased. No increase in survival occurred in milk neutrophils from these cows in response to GMCSF stimulation, suggesting the likely contribution of this factor to the apoptosis delay associated with this disease. Moreover, GMCSF was able to delay the apoptosis of blood neutrophils from both healthy and subclinical mastitis affected cows, suggesting that this survival factor accumulates and exerts its effects only at the site of inflammation in this disease.

Human neutrophils express both pro- and antiapoptotic members of the Bcl-2 family and the balance between them can determine whether neutrophils will undergo apoptosis (Reed, 1997). Granulocyte-macrophage colony-stimulating factor-mediated survival pathway in neutrophils occurs temporally with enhanced expression of the antiapoptotic protein Mcl1 (Epling-Burnette et al., 2001) and with decreased expression of the proapoptotic protein Bax (Dibbert et al., 1999). In eosinophils, stimulation with GMCSF results in up-regulation of Bcl- $\mathrm{x}_{\mathrm{L}}$, a STAT5 target gene (Dibbert et al., 1998). In addition, induction of neutro-

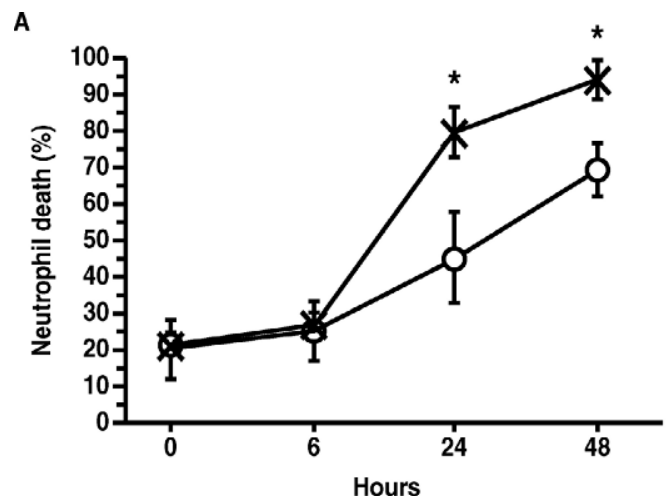

B

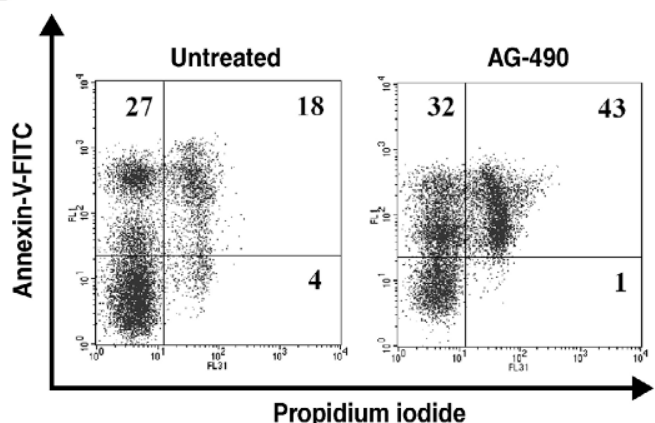

C

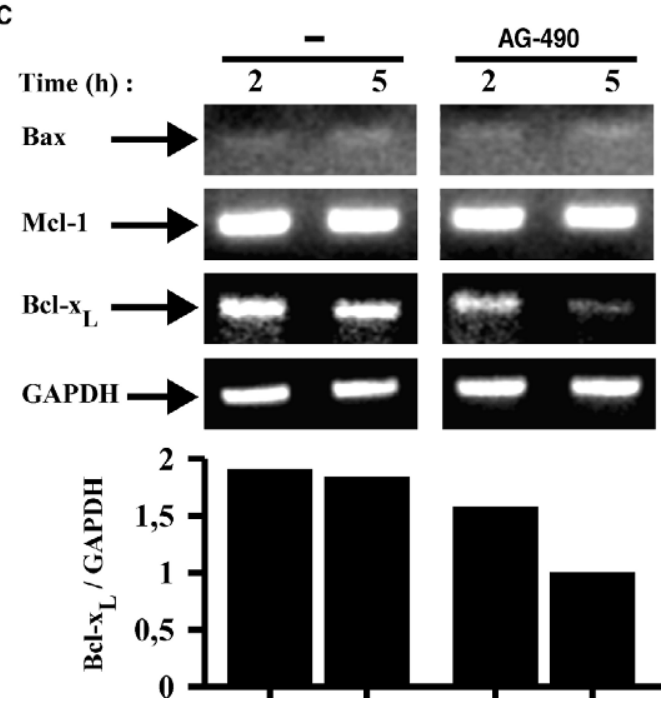

Figure 9. AG-490 induces apoptosis and Bcl- $x_{\mathrm{L}}$ down-regulation in milk neutrophils from subclinical mastitis-affected cows. Cells were obtained from cows with $\mathrm{SCC}>10^{6}$ cells $/ \mathrm{mL}$ and were cultured in the presence $(\mathbf{x})$ or absence $(\mathbf{o})$ of AG-490 $(200 \mu M)$. (A) Kinetic analysis of apoptosis of AG-490-treated neutrophils. Data are presented as means $\pm \mathrm{SD}(\mathrm{n}=6)$. *Significantly different from values obtained with untreated cells for $P<0.001$. (B) Representative flow cytometry analysis using dual color annexin-V-fluorescein (FITC) and propidium iodide staining at $24 \mathrm{~h}$. The percentage of single- or doublepositive cells in the individual quadrants is shown. (C) mRNA levels assessed by reverse transcription-PCR for expression of Bax, Mcl-1, and Bcl- $x_{L}$. As a control for quantification, glyceraldehyde-3-phosphate dehydrogenase (GAPDH) was also amplified. Filled columns show the ratio between Bcl- $\mathrm{x}_{\mathrm{L}}$ and GAPDH mRNA, as determined by densitometry analyses. These results are representative of at least 3 comparable experiments. 
phil apoptosis by tumor necrosis factor- $\alpha$ is associated with a reduction of expression of the antiapoptotic Bcl$\mathrm{x}_{\mathrm{L}}$ protein (Weinmann et al., 1999), suggesting a key role for this protein in neutrophil apoptosis regulation. Here, we demonstrate in bovine blood neutrophils that GMCSF activates STAT5 but not STAT3, and induces an increase in the mRNA of Bcl- $x_{\mathrm{L}}$ but not Bax and Mcl-1, and that STAT5 inhibition abrogates the prosurvival effect of GMCSF. In milk cells from subclinical mastitis-affected cows, active STAT5 complexes were detected and a prolonged survival of neutrophils was observed when compared with healthy milk. Taken together, these observations suggest that the regulation of Bcl- $\mathrm{x}_{\mathrm{L}}$ by STAT5 contributes to GMCSFdelayed apoptosis in milk neutrophils from subclinical mastitis-affected cows.

Complete STAT5 inhibition by AG-490 reversed GMCSF-induced apoptosis delay in blood neutrophils from both healthy and subclinical mastitis-affected cows. Moreover, GMCSF-induced Bcl- $x_{L}$ mRNA upregulation was blocked by AG-490. Treatment with this Jak inhibitor was shown to partially reverse the GMCSF-mediated protection from apoptosis in human neutrophils, even at doses of $200 \mu M$, with a dosedependent inhibition of GMCSF-induced Mcl-1 expression (Epling-Burnette et al., 2001). However, a GMCSF dose of $1000 \mathrm{U} / \mathrm{mL}$ was used, which is 10fold higher than ours, and could explain the difference observed. Furthermore, a recent study demonstrated that GMCSF-delayed apoptosis and phosphorylation of STAT3 and STAT5 were inhibited by AG-490 but that the level of Mcl-1 protein was not associated with neutrophil apoptosis (Sakamoto et al., 2003). Moreover, prevention of Jak2 phosphorylation by AG-490 is associated with the inability of GMCSF to prevent eosinophil apoptosis (Miike et al., 1999). In the present study, by using a $200 \mu M$ dose of AG-490, apoptosis was dramatically induced in milk neutrophils from subclinical mastitis-affected cows, with a time-dependent down-regulation in Bcl- $\mathrm{x}_{\mathrm{L}}$ mRNA. Therefore, these findings are consistent with the involvement of a STAT5 pathway in GMCSF-induced Bcl- $\mathrm{x}_{\mathrm{L}}$ up-regulation in mastitis milk neutrophils.

Neutrophils contribute to the elimination of pathogens and amplify the inflammatory response by the production of cytokines (Cassatella, 1999). Thus, we may hypothesize that the apoptosis delay observed in milk neutrophils from subclinical mastitis-affected cows contributes to generate autoregulatory feedback loops perpetuating inflammation. Then, the induction of neutrophil apoptosis may represent a target for the control of persistent accumulation of cells in the udder. Our data demonstrated that AG- 490 did not accelerate neutrophil apoptosis in blood but only at the site of inflammation, a finding consistent with results indicating that in vivo AG-490 treatment does not affect the survival of normal cells and does not block the function of immune cells (Burdelya et al., 2002). Further studies are needed to determine whether induction of neutrophil apoptosis in milk from subclinical mastitis-affected cows could have therapeutic application in the resolution of persistent inflammation of the bovine mammary gland. In addition, the questions of whether such a treatment could affect host defense mechanisms or enhance the virulence of the pathogen have to be elucidated.

\section{CONCLUSIONS}

The present study shows for the first time the existence of an apoptosis delay in milk neutrophils from subclinical mastitis-affected cows, which could be due to GMCSF. Furthermore, our results also provide insight into intracellular events necessary for GMCSFmediated regulation of apoptosis in bovine neutrophils. Our data suggest a role for a STAT5 pathway in GMCSF-induced Bcl- $x_{L}$ up-regulation. Because apoptosis of neutrophils plays an important role in the resolution of inflammation, the possible reversal of this antiapoptotic pathway may represent a target for the control of persistent accumulation of neutrophils in milk. As AG-490 is well tolerated in vivo, this inhibitor could be a potential therapeutic agent in the resolution of persistent inflammation of the bovine mammary gland.

\section{ACKNOWLEDGMENTS}

We thank M. Deliège, I. Sbaï, and M. Leblond for excellent technical and secretarial assistance. The Laboratory of the Milk Committee is thanked for the cell-count performance. Authors are grateful to DeLaval N.V. (Belgium) for providing the DeLaval Cell Counter. We also thank A. Collienne and C. Jacoby for providing milk samples. This work was supported by Janssen Animal Health (Belgium); we are especially grateful to K. Vlaminck and D. Hoeben for advice. P. B. and D. B. are Research Fellows from the Fonds pour la Formation à la Recherche dans l'Industrie et dans l'Agriculture (FRIA, Belgium). L. G., A. V., and F. B. are Research Fellow, Senior Research Associate, and Postdoctoral Researcher of the Fonds National Belge de la Recherche Scientifique (FNRS, Belgium), respectively.

\section{REFERENCES}

Adams, J. M., and S. Cory. 1998. The Bcl-2 protein family: Arbiters of cell survival. Science 281:1322-1326. 
Al-Shami, A., W. Mahanna, and P. H. Naccache. 1998. Granulocytemacrophage colony-stimulating factor-activated signaling pathways in human neutrophils: Selective activation of Jak2, Stat3, and Stat5b. J. Biol. Chem. 273:1058-1063.

Boulanger, D., F. Bureau, D. Mélotte, J. Mainil, and P. Lekeux. 2003. Increased nuclear factor $\mathrm{kB}$ activity in milk cells of mastitisaffected cows. J. Dairy Sci. 86:1259-1267.

Brach, M. A., S. deVos, H. J. Gruss, and F. Herrmann. 1992. Prolongation of survival of human polymorphonuclear neutrophils by granulocyte-macrophage colony-stimulating factor is caused by inhibition of programmed cell death. Blood 80:2920-2924.

Brizzi, M. F., M. G. Aronica, A. Rosso, G. P. Bagnara, Y. Yarden, and L. Pegoraro. 1996. Granulocyte-macrophage colony-stimulating factor stimulates JAK2 signaling pathway and rapidly activates p93fes, STAT1 p91, and STAT3 p92 in polymorphonuclear leukocytes. J. Biol. Chem. 271:3562-3567.

Burdelya, L., R. Catlett-Falcone, A. Levitzki, F. Cheng, L. B. Mora, E. Sotomayor, D. Coppola, J. Sun, S. Sebti, W. S. Dalton, R. Jove, and H. Yu. 2002. Combination therapy with AG-490 and interleukin 12 achieves greater antitumor effects than either agent alone. Mol. Cancer Ther. 1:893-899.

Cassatella, M. A. 1999. Neutrophil-derived proteins: Selling cytokines by the pound. Adv. Immunol. 73:369-509.

Colotta, F., F. Re, N. Polentarutti, S. Sozzani, and A. Mantovani. 1992. Modulation of granulocyte survival and programmed cell death by cytokines and bacterial products. Blood 80:2012-2020.

Dibbert, B., I. Daigle, D. Braun, C. Schranz, M. Weber, K. Blaser, U. Zangemeister-Wittke, A. N. Akbar, and H. U. Simon. 1998. Role for Bcl- $\mathrm{x}_{\mathrm{L}}$ in delayed eosinophil apoptosis mediated by granulocyte-macrophage colony-stimulating factor and interleukin-5. Blood 92:778-783.

Dibbert, B., M. Weber, W. H. Nikolaizik, P. Vogt, M. H. Schoni, K. Blaser, and H. U. Simon. 1999. Cytokine-mediated Bax deficiency and consequent delayed neutrophil apoptosis: A general mechanism to accumulate effector cells in inflammation. Proc. Natl. Acad. Sci. USA 96:13330-13335.

Epling-Burnette, P. K., B. Zhong, F. Bai, K. Jiang, R. D. Bailey, R. Garcia, R. Jove, J. Y. Djeu, T. P. Loughran, Jr., and S. Wei. 2001. Cooperative regulation of Mcl-1 by Janus kinase/stat and phosphatidylinositol 3-kinase contribute to granulocyte-macrophage colony-stimulating factor-delayed apoptosis in human neutrophils. J. Immunol. 166:7486-7495.

Garlichs, C. D., S. Eskafi, I. Cicha, A. Schmeisser, B. Walzog, D. Raaz, C. Stumpf, A. Yilmaz, J. Bremer, J. Ludwig, and W. G. Daniel. 2004. Delay of neutrophil apoptosis in acute coronary syndromes. J. Leukoc. Biol. 75:828-835.

Gouilleux, F., C. Pallard, I. Dusanter-Fourt, H. Wakao, L. A. Haldosen, G. Norstedt, D. Levy, and B. Groner. 1995. Prolactin, growth hormone, erythropoietin and granulocyte-macrophage colony stimulating factor induce MGF-Stat5 DNA binding activity. EMBO J. 14:2005-2013.

Harmon, R. J. 1994. Physiology of mastitis and factors affecting somatic cell counts. J. Dairy Sci. 77:2103-2112.
Haslett, C. 1999. Granulocyte apoptosis and its role in the resolution and control of lung inflammation. Am. J. Respir. Crit. Care Med. 160:S5-S11.

Kieslinger, M., I. Woldman, R. Moriggl, J. Hofmann, J. C. Marine, J. N. Thle, H. Beug, and T. Decker. 2000. Antiapoptotic activity of Stat5 required during terminal stages of myeloid differentiation. Genes Dev. 14:232-244.

Kirken, R. A., R. A. Erwin, D. Taub, W. J. Murphy, F. Behbod, L. Wang, F. Pericle, and W. L. Farrar. 1999. Tyrphostin AG-490 inhibits cytokine-mediated JAK3/STAT5a/b signal transduction and cellular proliferation of antigen-activated human T cells. J. Leukoc. Biol. 65:891-899.

Kisseleva, T., S. Bhattacharya, J. Braunstein, and C. W. Schindler. 2002. Signaling through the JAK/STAT pathway, recent advances and future challenges. Gene 285:1-24.

Klei, L., J. Yun, A. Sapru, J. Lynch, D. Barbano, P. Sears, and D. Galton. 1998. Effects of milk somatic cell count on cottage cheese yield and quality. J. Dairy Sci. 81:1205-1213.

Levitzki, A. 1999. Protein tyrosine kinase inhibitors as novel therapeutic agents. Pharmacol. Ther. 82:231-239.

Miike, S., A. Nakao, M. Hiraguri, K. Kurasawa, Y. Saito, and Y. Iwamoto. 1999. Involvement of JAK2, but not PI 3-kinase/Akt and MAP kinase pathways, in anti-apoptotic signals of GMCSF in human eosinophils. J. Leukoc. Biol. 65:700-706.

Murphy, S. C., K. Cranker, G. F. Senyk, D. M. Barbano, A. I. Saeman, and D. M. Galton. 1989. Influence of bovine mastitis on lipolysis and proteolysis in milk. J. Dairy Sci. 72:620-626.

Reed, J. C. 1997. Double identity for proteins of the Bcl-2 family. Nature 387:773-776.

Saba, S., G. Soong, S. Greenberg, and A. Prince. 2002. Bacterial stimulation of epithelial G-CSF and GMCSF expression promotes PMN survival in CF airways. Am. J. Respir. Cell Mol. Biol. 27:561-567.

Sakamoto, C., K. Suzuki, F. Hato, M. Akahori, T. Hasegawa, M. Hino, and S. Kitagawa. 2003. Antiapoptotic effect of granulocyte colonystimulating factor, granulocyte-macrophage colony-stimulating factor, and cyclic AMP on human neutrophils: Protein synthesisdependent and protein synthesis-independent mechanisms and the role of the Janus kinase-STAT pathway. Int. J. Hematol. $77: 60-70$.

Simon, H. U. 2003. Neutrophil apoptosis pathways and their modifications in inflammation. Immunol. Rev. 193:101-110.

Turlej, R. K., L. Fiévez, C. F. Sandersen, S. Dogń, N. Kirschvink, P. Lekeux, and F. Bureau. 2001. Enhanced survival of lung granulocytes in an animal model of asthma: Evidence for a role of GMCSF activated STAT5 signalling pathway. Thorax 56:696-702.

Wei, S., J. H. Liu, P. K. Epling-Burnette, A. M. Gamero, D. Ussery, E. W. Pearson, M. E. Elkabani, J. I. Diaz, and J. Y. Djeu. 1996. Critical role of Lyn kinase in inhibition of neutrophil apoptosis by granulocyte-macrophage colony-stimulating factor. J. Immunol. 157:5155-5162.

Weinmann, P., P. Gaehtgens, and B. Walzog. 1999. Bcl-Xl- and Baxalpha-mediated regulation of apoptosis of human neutrophils via caspase-3. Blood 93:3106-3115. 